\title{
Comparative morphology of tongue surface in Neotropical aerial insectivore bats (Mammalia: Chiroptera)
}

\author{
Renato Gregorin' \& Patrícia Araújo Zanatta² \\ ${ }^{1}$ Universidade Federal de Lavras (UFLA), Departamento de Biologia, Centro de Biodiversidade e Recursos Genéticos. Lavras, MG, Brasil. \\ ORCID: http://orcid.org/0000-0002-2324-3203. E-mail: rgregorin@dbi.ufla.br \\ 2 Independent researcher. Poços de Caldas, MG, Brasil. \\ ORCID: http://orcid.org/0000-0001-6938-2594. E-mail: pati.a.zanatta@gmail.com
}

\begin{abstract}
Comparative morphological characters in Neotropical bats are mostly restricted to external and cranio-dentary complexes, and few studies focusing on other morphological complexes have been carried out. In the case of tongue morphology, comparative analyses of the structure have been restricted to the superfamily Noctilionoidea with a wide range of diets, and Molossidae, a strictly aerial insectivore family. In this paper, we studied the morphology of tongue papillae in 10 aerial insectivore Neotropical bat species, representing six families (Emballonuridae, Furipteridae, Thyropteridae, Mormoopidae, Natalidae, and Vespertilionidae), and data from the previous study of Molossidae were compared. We studied tongues in light and scanning electron microscopes following material preparation protocols. We observed two types of sensitive papillae, circumvallate and fungiform, the latter at times presenting a groove surrounding the papillae. Nine mechanic types were observed, one of them, which we called flaky-like, not hitherto described. All Vespertilionoidea families (Vespertilionidae, Natalidae, and Molossidae) presented, as diagnosing characters, fungiform papillae distributed throughout the tongue, as well as anteriorly at the dorsum, and scale-like papillae on the medial lobe directed laterally and anteriorly. Emballonuridae showed the simplest tongue morphology regarding the presence and abundance of some papillae. Families composing the clade Furipteridae + Thyropteridae + Mormoopidae presented small and non-grooved fungiform papillae, and mechanical bifid papillae were absent. In summary, this study has provided additional traits (putative synapomorphies) of the bat tongue to support the clades on the current bat phylogeny.
\end{abstract}

Keywords. Tongue papillae structure; Comparative anatomy; New World bats; Scanning electron microscopy.

\section{INTRODUCTION}

Chiroptera is one of the most diverse orders within mammals in regards to taxonomic richness, morphology, and habits (Simmons \& Conway, 2003), including diet. While species of most bat families are primarily aerial insectivores, species of some families have independently evolved other dietary habits, e.g., nectarivory and frugivory in Phyllostomidae and Pteropodidae, carnivory (i.e., preying on small vertebrates) in Megadermatidae and Phyllostomidae, piscivory in Vespertilionidae, Nycteridae, and Noctilionidae, and uniquely, hematophagy in Phyllostomidae (Gardner, 1977; Ferrarezzi \& Gimenez, 1996). This great variety of feeding habits is reflected in several morphological complexes and specializations, including tongue morphology (Freeman, 1979, 1998, 2000; Ferrarezzi \& Gimenez, 1996; Monteiro \& Nogueira, 2009; Rossoni et al., 2019). Tongues in bats vary in size, from very short in some insec- tivores (e.g., Lasiurus) and short-faced frugivores (e.g., Ametrida, Pygoderma) to very long as in nectarivores. They can be rich in papillae, particularly cornified ones, as in Molossidae, or with few papillae as in Emballonuridae. However, in general, bat tongues are light brown, flexible, and with papilla and keratinization on the dorsal and lateral surfaces. Gimenez et al. (1996) described a high degree of morphological diversification in tongue papillae within the New World Phyllostomidae, corresponding to a highly diverse range of food items, ranging from fruits, nectar and pollen, and leaves, to arthropods, small vertebrates, and blood. However, within each of the dietary groups, there was a surprisingly high diversity of tongue papillae even considering a similar diet, for example, the variety of tongue papillae present in nectar-feeding bat species compared to the homogeneous material, in terms of physical properties, found in nectar. These observations indicate that besides particular adaptations to get and process 
food, such as sensibility and manipulation, other aspects may be contributing to the observed morphological variation such as phylogeny (Gimenez et al., 1996; Ferrarezzi \& Gimenez, 1996; Rossoni et al., 2019). Gregorin (2003) also observed high variation when comparing the morphology of the tongue surface in several free-tailed bat genera. The author also observed high variation in the lingual papillae in these strict aerial insectivore bats that prey mainly on moths and beetles.

Tongue morphology is relatively well-studied mainly in Neotropical bats in families such as Phyllostomidae (Park \& Hall, 1951; Greenbaum \& Phillips, 1974; Howell \& Hodkin, 1976; Griffths, 1982; Uieda, 1986; Griffths \& Criley, 1989; Gimenez et al., 1996; Wetterer et al., 2000; Harper et al., 2013) and Molossidae (Gregorin 2003). On the other hand, there are only a few studies published focusing on other families, and those available are mainly from particular Old World species such as Miniopterus schreiberse (Huhl, 1817) (Miniopteridae Kobayashi \& Shimamura, 1982), Pipistrellus pipistrellus (Schreber, 1774) (Vespertilionidae - Pastor et al., 1993), Cynopterus brachyotis (Müller, 1838) (Pteropodidae - Emura et al., 2001), Eidolon helvum (Ker, 1792) (Pteropodidae - Abayomi, 2009), and Rousettus aegyptiacus (É. Geoffroy, 1810) (Pteropodidae - Jackowiak et al., 2009; Abumandour, 2014). For the Neotropical region, there are few published studies on tongue morphology beyond the mentioned Phyllostomidae, Molossidae (see references above), Mormoopidae, and Noctilionidae (e.g., Wetterer et al., 2000), but for other speciose families, like Vespertilionidae and Emballonuridae, no study has been published. Gimenez (1993) in an unpublished thesis provided a brief description of papillae tongue morphology of many species of all Neotropical bat families using optic microscopy. Therefore, here we reanalyzed the tongue of some of the species studied by Gimenez (1993) and additional species using scanning electron microscopy images, and elaborated on a descriptive and analytical comparative study of the papilla and overall morphology of the tongue in those bats. In this sense, the scope of this study was to describe the tongue papillae of individuals representing 10 species allocated into six families of Neotropical aerial insectivore bats using scanning electron microscopy techniques and to com- pare the observed patterns with other Neotropical insectivore bats.

\section{MATERIAL AND METHODS}

The study comprised of an analysis of 35 specimens of 10 species from six Neotropical families of aerial insectivore bats (Table 1). Considering that bats are a very speciose group, the scope of this study is to provide an introduction to this issue. Certainly, more specimens and taxa are desired to have a better overview about the individual and taxonomic variation in the tongue morphology of Neotropical bats. The supra-familial phylogenetic grouping was done according to the study by Teeling et al., (2005): Emballonuridae in the superfamily Emballonuroidea; Furipteridae, Thyropteridae, and Mormoopidae in the superfamily Noctilionoidea; and Natalidae and Vespertilionidae in the superfamily Vespertilionoidea. All studied specimens were fluid-preserved and are housed at the Mammal Collection at the Federal University of Lavras (CMUFLA), Lavras, Brazil. The observations of these samples were compared to available data of two other Neotropical families, Molossidae (Gregorin, 2003) and animalivore species of Phyllostomidae (Gimenez et al., 1996; Wetterer et al., 2000).

\section{Material preparation and analyses}

The tongue surface morphology was assessed in two steps. To detect variability of gross morphology of papillae and general aspects of the tongues, a wider series of all 33 specimens were studied using a stereomicroscope (Table 1). For this step, the tongues were dried, thus making it easier to obtain a first overview of the papillae (e.g., types, distribution, quantity, and relative size). The second step focused on tongues from selected specimens (Table 1), using scanning electron microscopy (SEM) that provided high-resolution images of the superficial structures (Fig. 1) and allowed a much more detailed analysis of the papillae. For this second procedure, the tongues were removed from the specimens by cutting the struc-

Table 1. Specimens of bats were investigated in this study.

\begin{tabular}{|c|c|c|}
\hline Family & Species & Collection number (CMUFLA) \\
\hline \multirow[t]{2}{*}{ Emballonuridae } & Peropteryx kappleri Peters, 1867 & $1487^{a, b}, 2506^{a, b}$, and $2510^{a}$ \\
\hline & Rhynchonycteris naso (Wied-Newied, 1820) & $1782^{\mathrm{a}, \mathrm{b}}$ \\
\hline Mormoopidae & Pteronotus rubiginosus (Wagner, 1843) & $1487^{\mathrm{a}}, 2583^{\mathrm{a}, \mathrm{b}}$, and $2584^{\mathrm{a}}$ \\
\hline Thyropteridae & Thyroptera wynneae Velazco, Gregorin, Voss \& Simmons, 2014 & $694^{a, b}$ and $1160^{a, b}$ \\
\hline Furipteridae & Furipterus horrens Cuvier, 1828 & $893^{\mathrm{a}}, 1574^{\mathrm{a}}, 1531^{\mathrm{a}}, 2503^{\mathrm{a}, \mathrm{b}}, 2666^{\mathrm{a}}$, and 2667a,b \\
\hline Natalidae & Natalus macrourus (Gervais, 1856) & $1122^{\mathrm{a}}, 1575^{\mathrm{a}, \mathrm{b}}, 2509^{\mathrm{a}}, 2519^{\mathrm{a}, \mathrm{b}}$, and $2668^{\mathrm{a}}$ \\
\hline \multirow[t]{5}{*}{ Vespertilionidae } & Eptesicus brasiliensis (Desmarest, 1819) & $970^{\mathrm{a}}, 1445^{\mathrm{a}, \mathrm{b}}, 2298^{\mathrm{a}}$, and $3212^{\mathrm{a}}$ \\
\hline & Eptesicus furinalis (D'0rbigny, 1847) & $2484^{\mathrm{a}, \mathrm{b}}$ \\
\hline & Histiotus velatus (I. Geoffroy, 1824) & $1414^{\mathrm{a}}, 2624^{\mathrm{a}, \mathrm{b}}, 2631^{\mathrm{a}}, 2646^{\mathrm{a}}$, and $2648^{\mathrm{a}, \mathrm{b}}$ \\
\hline & & $2483^{\mathrm{a}}, 2614^{\mathrm{a}}$, and $2953^{\mathrm{a}}$ \\
\hline & Lasiurus blossevillii ([Lesson, 1826]) & $2346^{\mathrm{a}}$ and $2483^{\mathrm{a}}$ \\
\hline
\end{tabular}

${ }^{\mathrm{a}}$ Tongue studied using the stereomicroscope.

${ }^{\mathrm{b}}$ Tongue studied using scanning electron microscopy. 


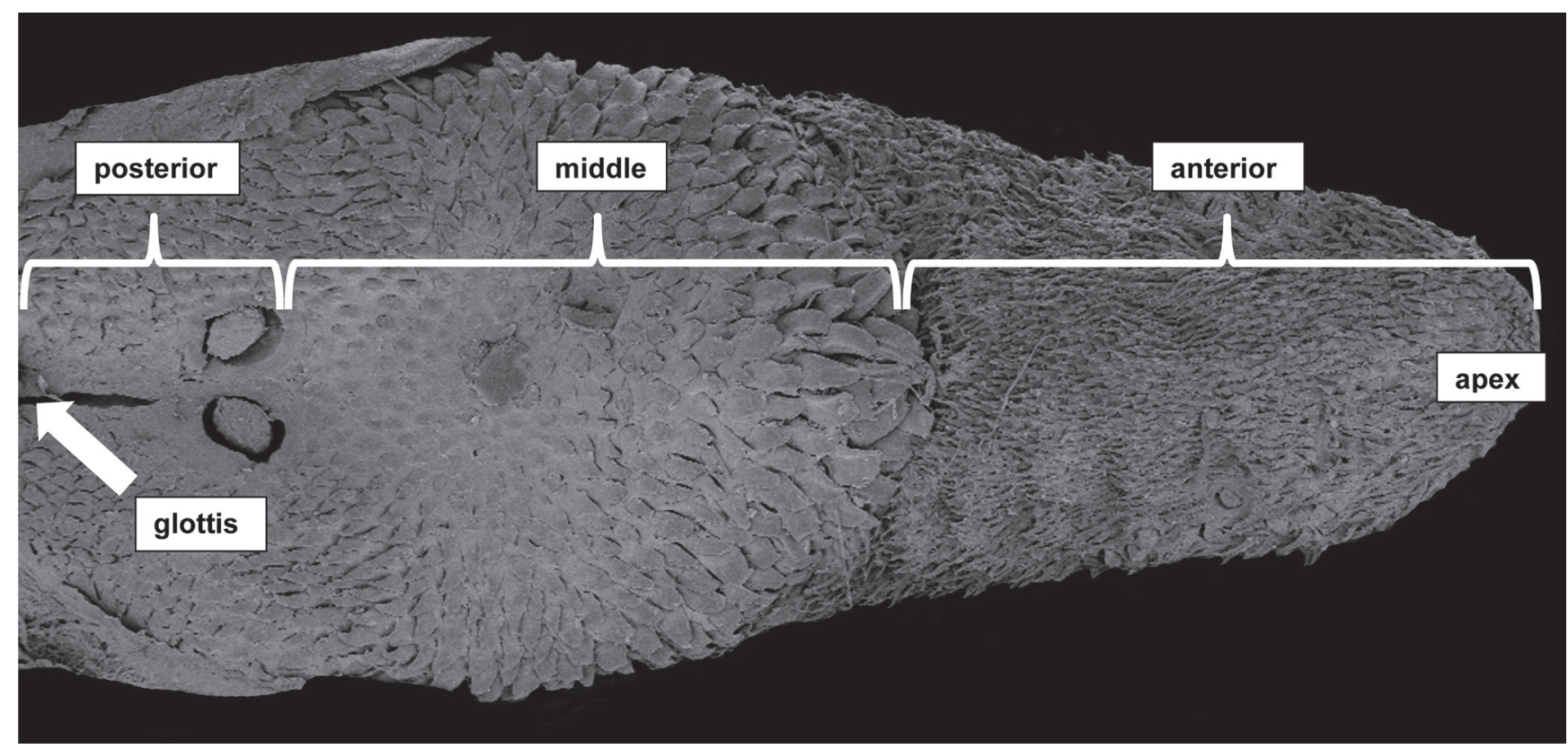

Figure 1. Dorsal surface of the tongue showing the general division in three regions to facilitate the description and distribution of the papillae.

ture at the glottis level using a scalpel. The tongues were first cleaned with a jet of alcohol and soft brush from gross residues, and in the next step, the tongues were cleaned under distilled water using ultrasound equipment (MaxiClean ${ }^{\odot}$ 1400) (Gregorin, 2003). The tongues were immersed in a modified Karnowsky solution of $\mathrm{pH} 7.2$ for 24 hours for fixation and subsequently were washed three times in a buffer solution of Cocadilate for 10 minutes (Pastor et al., 1993; Harper et al., 2013). Then, the tongues were dehydrated via an acetone gradient using concentrations of $25,50,75,90$, and $100 \%$, for 10 minutes each. After these preparations, the tongues were glued to stubs using a conductive adhesive, and dried to a critical point with $\mathrm{CO}_{2}$. Dehydration by both procedures, acetone and critical point, is an important step to obtain better images. The tongues were then coated with gold to obtain a better conductive material. The tongues were analyzed in a Carl Zeiss' $\mathrm{EVO}^{\circ} 40$ electron scanning microscope at the Electron Microscopy
Laboratory at UFLA. All material is available at CMUFLA preserved in a silica gel dry environment.

\section{Tongue and papillae nomenclature}

The tongue was divided into three regions based on the general arrangement of the papillae in dorsal view as in Abumandour (2014) (Fig. 1): (1) anterior - from apex to approximately the middle of the tongue, where the papillae deeply change shape and/or direction, and in some taxa, where a protuberance or lobe is present; (2) middle - from the region where the papillae have changed direction or shape, or from where a protuberance or lobe is present to the dorsal circumvallate papillae; and (3) posterior - the posteriormost region of the tongue, from the dorsal circumvallate papillae to the glottis (pharyngeal region of the tongue) (Fig. 1). The study follows the papillae nomenclature used by Pastor et al. (1993), Gimenez

Table 2. Matrix of distribution of characters as described in the text.

\begin{tabular}{|c|c|c|c|c|c|c|c|c|c|c|c|c|c|c|c|c|c|c|c|c|}
\hline Taxon/Character & 1 & 2 & 3 & 4 & 5 & 6 & 7 & 8 & 9 & 10 & 11 & 12 & 13 & 14 & 15 & 16 & 17 & 18 & 19 & 20 \\
\hline Peropteryx kappleri & 0 & 0 & 0 & 0 & 0 & 0 & 0 & 0 & 1 & 0 & 0 & 0 & 0 & 0 & 0 & 0 & 0 & $?$ & 0 & 0 \\
\hline Rhynchonycteris naso & 0 & 0 & 0 & 0 & 0 & 0 & 0 & 0 & 0 & 0 & 0 & 0 & 0 & 0 & 0 & 0 & 0 & $?$ & 0 & 0 \\
\hline Natalus macrourus & 1 & 1 & 0 & 1 & 0 & 0 & 0 & 0 & 0 & 1 & 1 & 0 & 0 & 1 & 1 & 1 & 0 & $?$ & 0 & 0 \\
\hline Eptesicus furinalis & 0 & 1 & 0 & 1 & 0 & 0 & 0 & 0 & 0 & 1 & 0 & 0 & 0 & 0 & 0 & 0 & 1 & 0 & 0 & 0 \\
\hline Eptesicus brasiliensis & 0 & 1 & 0 & 1 & 0 & 0 & 0 & 0 & 0 & 1 & 0 & 0 & 0 & 0 & 0 & 0 & 1 & 0 & 0 & 0 \\
\hline Histiotus velatus & 0 & 1 & 0 & 1 & 0 & 0 & 0 & 0 & 0 & 1 & 0 & 0 & 0 & 0 & 0 & 0 & 0 & $?$ & 0 & 0 \\
\hline Lasiurus blossevillii & 0 & 2 & 0 & 1 & 0 & 0 & 0 & 0 & 0 & 1 & 1 & 0 & 0 & 0 & 0 & 0 & 0 & $?$ & 0 & 0 \\
\hline Tadarida brasiliensis & 0 & 2 & 0 & 1 & 0 & 0 & 0 & 1 & 1 & 1 & 0 & 0 & 0 & 0 & 0 & 1 & 1 & 1 & 0 & 0 \\
\hline Cynomops abrasus & 0 & 2 & 0 & 1 & 0 & 0 & 0 & 1 & 1 & 1 & 0 & 0 & 0 & 0 & 0 & 1 & 1 & 1 & 0 & 0 \\
\hline Furipterus horrens & 1 & 0 & 1 & 0 & 0 & 1 & 1 & 1 & $?$ & 2 & 0 & 0 & 0 & 0 & 1 & 0 & 0 & $?$ & 1 & 0 \\
\hline Thyroptera wynneae & 1 & 0 & 0 & 0 & 1 & 0 & 1 & 0 & $?$ & 1 & 0 & 0 & 1 & 0 & 0 & 0 & 0 & $?$ & 0 & 0 \\
\hline Pteronotus rubginosus & 0 & 0 & 0 & 0 & 1 & 0 & 1 & 0 & $?$ & 2 & 1 & 1 & 1 & 0 & 1 & 0 & 0 & $?$ & 0 & 1 \\
\hline Noctilio albiventris & 0 & 0 & 1 & 0 & 0 & 0 & 0 & 1 & 1 & 0 & 1 & 0 & 0 & 0 & 0 & 0 & 1 & 0 & 0 & 1 \\
\hline Micronycteris megalotis & 1 & 0 & 0 & 0 & 1 & 0 & 1 & 0 & $?$ & 0 & 0 & 0 & 0 & 0 & 1 & 0 & 0 & $?$ & 0 & 1 \\
\hline Mimon bennettii & 1 & 0 & 0 & 0 & 1 & 0 & 1 & 0 & $?$ & 0 & 0 & 0 & 0 & 0 & 1 & 0 & 0 & $?$ & 0 & 1 \\
\hline
\end{tabular}


et al. (1996), and Abumandour (2014). Two morphometrical variables, the total length of the tongue (from apex to glottis), and width of the tongue (taken from the middle region of the tongue) were taken as well as the ratio between both variables (Table 2).

In addition, to analytically observe the distribution papillae along the bat lineages, parsimony analysis of character's optimization was carried out over a con- strained tree based on Teeling et al. (2005). A character matrix (Table 2 ) was built using Winclada ${ }^{\odot}$ version 1.00 .08 considering the multi-state character as non-additive, and no prior polarization was done. The global parsimony was carried out at TNT (Goloboff et al., 2008) using the exact algorithm "implicit enumeration". Tree view and character optimization were done using Winclada. The characters $(\mathrm{Ch})$ and their states are described as follows:
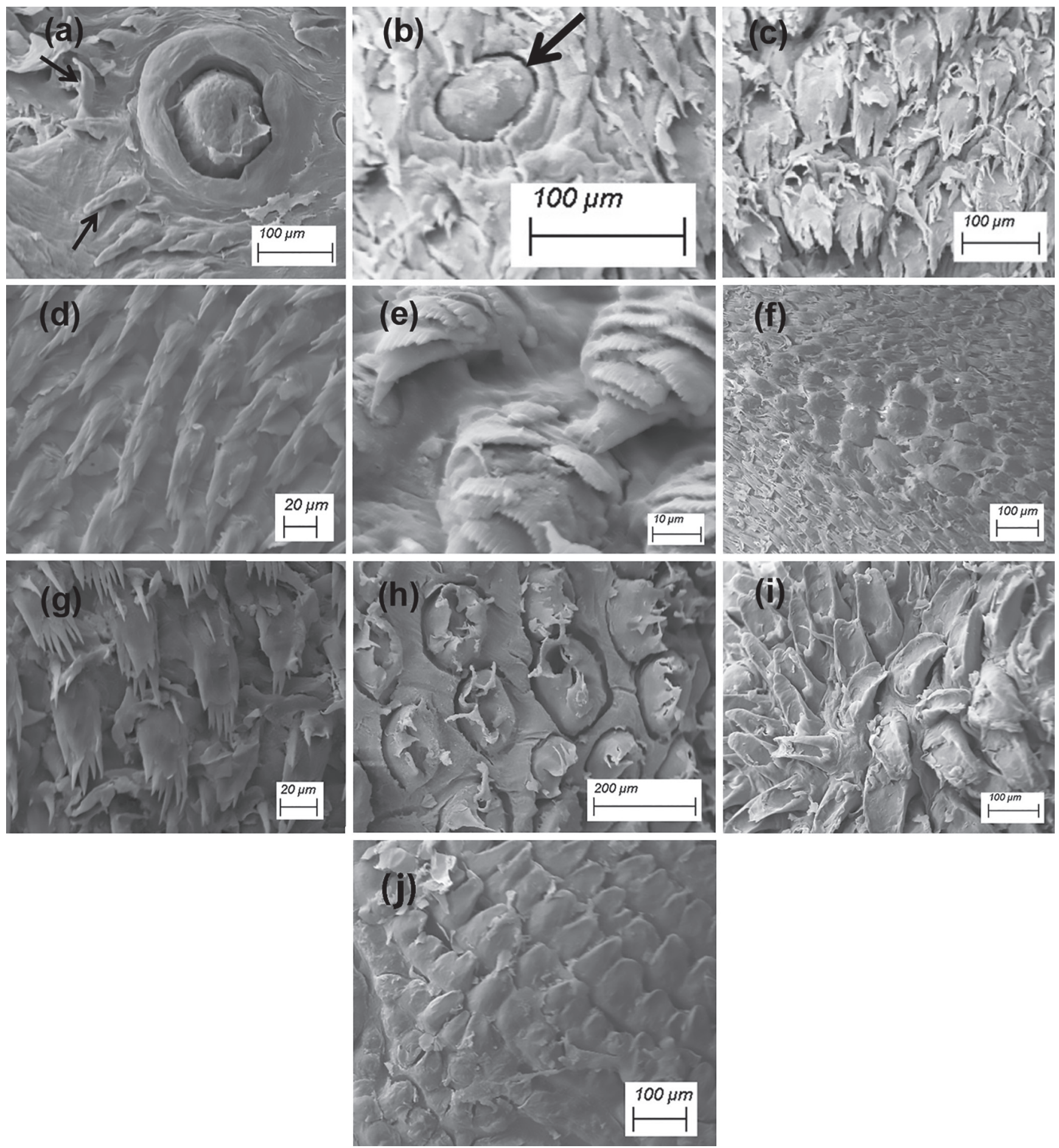

Figure 2. Types of lingual papillae observed in Neotropical aerial insectivore bats: (a) Circumvallate with remarkable sulcus and integument, surrounded by pointed basal filiform (arrows); (b) Fungiform with notable sulcus (arrow); (c) Bifid filiform; (d) Strictly filiform; (e) Flacky-like filiform, note the layered structure with dentate keratinous plates; (f) Giant filiform (center), note the bigger size than the surrounding papillae; (g) Digitiform filiform; (h) Crown-shaped filiform, note the bulbous base and delicate filamentous projections at the apical edge; (i) Scale-like filiform, note the rectangular-shaped and dorsally concave structure; and (j) Triangular filiform. 
Ch 1 Total length of glottis: $0=$ short, $1=$ long; Ch 2 Middorsal region of the tongue: $0=$ plain, $1=$ with a protuberance, 2 = with a lobe; Ch 3 Region between the dorsal circumvallate papillae: $0=$ smooth, $1=$ covered by papillae; Ch 4 Surface of dorsal circumvallate papillae: $0=$ smooth, 1 = lobed; Ch 5 Lateral circumvallate papillae: $0=$ absent, 1 = present; Ch 6 Dorsal fungiform papillae: $0=$ present, $1=$ absent; $C h 7$ Lateral fungiform papillae: $0=$ present, 1 = absent; Ch 8 relative size of dorsal fungiform papillae: $0=$ small, 1 = large; Ch 9 Arrangement of the lateral fungiform papillae: 0 = irregular, 1 = linear; Ch 10 Arrangement of filiform papillae at the mid-dorsal region: $0=$ concentric, $1=$ eccentric, $2=$ posteriorly directed; Ch 11 arrangement of filiform papillae at the mid-anterior region: 0 = irregular, 1 = linearly arranged; Ch 12 Crown-shaped filiform papillae: $0=$ absent, $1=$ present; Ch 13 Digitiform filiform papillae: $0=$ absent, 1 = present; Ch 14 Flaky-like filiform papillae: $0=$ absent, 1 = present; Ch 15 Bifid filiform papillae: $0=$ absent, $1=$ present; Ch 16 Strictly filiform papillae: $0=$ present, $1=$ absent; Ch 17 Scale-shaped filiform papillae: $0=$ absent, 1 = present; Ch 18 Relative development of scale-shaped papillae: $0=$ reduced; 1 = large; Ch 19 Triangular filiform papillae: 0 = absent, 1 = present; Ch 20 Giant filiform papillae: $0=$ absent, $1=$ present.

\section{RESULTS}

\section{Papillae description}

A total of 11 types of lingual papillae were observed in the studied bats included in the two functional classes as illustrated in Fig. 2: two types of taste papillae and nine mechanical (cornified) ones. Taste papillae were the circumvallate (Fig. 2A) with several levels of development in the sulcus surrounding the integument, and fungiform papillae with or without prominent groove surrounding the globular structure (Fig. 2B). Nine types of mechanical papillae were observed: (1) Bifid filiform papillae are basally bulbous with two prominent and keratinous branches projecting distally (V-shaped edge), and the bulbous basal portion fringed with short projections (Fig. 2C); (2) strictly filiform papillae are elongated, sharp, monofid or composed of small projections along the axis (Fig. 2D); when monofid, it resembles the conical papilla but occurs in distinct portions of the tongue; (3) Flaky-like is a type of filiform papilla not previously described in literature; this papilla is characterized by having layers of keratin instead of filamentous projections; flaky-like papillae are composed of concentric and serrated (dentate) plates resembling overlapping scales (Fig. 2E); (4) Giant filiform papillae stand out from the surrounding papillae due to their very large size and small anterior projections, always placed dorsally near the apex of the tongue (Fig. 2F); (5) Digitiform filiform papillae are basally bulbous in which five to seven prominent finger-like projections are observed (Fig. 2G); (6) Crown filiform papillae are rounded and basely numb, with several short filamentous projections from the distal edge
(Fig. 2H); (7) Basal filiform papillae are distributed across the dorsal and/or laterally distributed at the base of the tongue; they usually are monofid (conical), fleshy, and sometimes curved (Fig. 2A); (8) Scale-like filiform papillae are distinct from strictly filiform in having a longer and rectangular central concavity, usually with blunt edges (Fig. 2l); and (9) Triangular filiform papillae are triangular-shaped and serially arranged from the middle to the posterior region of the tongue (Fig. $2 \mathrm{~J}$ ).

\section{Distribution of papillae among the taxa}

Superfamily Emballonuroidea, family Emballonuridae - The tongue is relatively short and narrow (Table 3 ) with a length/width ratio of 2.8 to 3.3. There was no medial lobe or any salience at the mid-dorsal portion of the tongue in both studied species Peropteryx kappleri and Rhynchonycteris naso. In P. kappleri a pair of circumvallate papillae dorsally located was observed, but the sulcus and the surrounding tegument were poorly developed (Fig. 3A). Fungiform papillae are distributed in two arrangements: one is composed by large papillae without sulci and is poorly distributed, concentrated in two or

Table 3. Morphometry of the tongue: TL: total length; W: width.

\begin{tabular}{|c|c|c|c|c|}
\hline Taxon & CMufla & TL & W & $\mathrm{TL} / \mathrm{W}$ \\
\hline \multirow[t]{3}{*}{ Peropteryx kappleri } & 890 & 9.21 & 3.15 & 2.9 \\
\hline & 2492 & 9.58 & 3.1 & 3.1 \\
\hline & 888 & 9.55 & 2.89 & 3.3 \\
\hline \multirow[t]{3}{*}{ Rhynchonycteris naso } & 1962 & 6.81 & 2.3 & 3.0 \\
\hline & 1960 & 7.17 & 2.33 & 3.1 \\
\hline & 1961 & 6.84 & 2.43 & 2.8 \\
\hline \multirow[t]{4}{*}{ Natalus macrourus } & 2509 & 8.4 & 2.82 & 3.0 \\
\hline & 1122 & 9.54 & 2.88 & 3.31 \\
\hline & 1575 & 8.92 & 2.81 & 3.17 \\
\hline & 2519 & 8.64 & 2.69 & 3.2 \\
\hline \multirow[t]{4}{*}{ Eptesicus furinalis } & 3283 & 1.75 & 3.23 & 2.9 \\
\hline & 1423 & 1.59 & 3.23 & 2.6 \\
\hline & 3132 & 1.86 & 3.64 & 2.6 \\
\hline & 2484 & 1.26 & 2.94 & 2.3 \\
\hline \multirow[t]{3}{*}{ Eptesicus brasiliensis } & 1446 & 9.41 & 3.43 & 2.7 \\
\hline & 3131 & 9.49 & 2.91 & 3.3 \\
\hline & 1445 & 8.79 & 2.85 & 3.1 \\
\hline \multirow[t]{4}{*}{ Histiotus velatus } & 1414 & 7.2 & 3.34 & 2.2 \\
\hline & 1413 & 6.5 & 2.91 & 2.2 \\
\hline & 2624 & 8.73 & 2.55 & 3.4 \\
\hline & 2648 & 9.2 & 3.27 & 2.8 \\
\hline \multirow[t]{5}{*}{ Furipterus horrens } & 1531 & 6.54 & 2.59 & 2.52 \\
\hline & 2666 & 6.52 & 2.5 & 2.6 \\
\hline & 852 & 6.6 & 2.34 & 2.8 \\
\hline & 2667 & 6.14 & 2.35 & 2.6 \\
\hline & 2503 & 6.05 & 2.61 & 2.3 \\
\hline \multirow[t]{2}{*}{ Thyroptera wynneae } & 1160 & 7.29 & 1.8 & 4.1 \\
\hline & 694 & 7.31 & 1.79 & 4.1 \\
\hline \multirow[t]{5}{*}{ Pteronotus rubginosus } & 758 & 11.99 & 2.36 & 5.1 \\
\hline & 2584 & 11.91 & 2.66 & 4.5 \\
\hline & 1484 & 12.24 & 2.97 & 4.2 \\
\hline & 1487 & 9.54 & 2.85 & 3.3 \\
\hline & 2583 & 9.91 & 3.23 & 3.1 \\
\hline
\end{tabular}


three transverse rows anterior to the circumvallate papillae (Fig. 3A); and the other group is comprised of small fungiform papillae, linearly arranged at the dorsolateral and posterior portion of the tongue, delimiting the distribution of basal papillae (Fig. 3B). At the medial portion of the tongue, strictly filiform papillae are concentrically arranged (Fig. 3 C). The dorsal surface of the tongue, from the apex to the middle, is covered by bifid filiform papillae, with a circular and fringed base, resulting in a tubular-shaped papilla (Fig. 3D); they are posteriorly directed, and become flat and filamentous in the posterior portion of the tongue, and are triangular in the lateral and posterior portions of the tongue. Basal filiform papillae are low, conical, and slightly curved (Fig. 3B). In R. naso, a pair of dorsal circumvallate papillae with a prominent membrane surrounding the groove was observed. Scattered, grooved, and small-sized fungiform papillae were observed only along the lateral and posterior portion of the tongue bordering the basal filiform papillae, like in P. kappleri; however, the basal filiform papillae in $R$. naso are somewhat filamentous. The remaining filiform papillae of $R$. naso correspond to those from $P$. kappleri, except those papillae anterior to the dorsal circumvallate that became relatively larger.
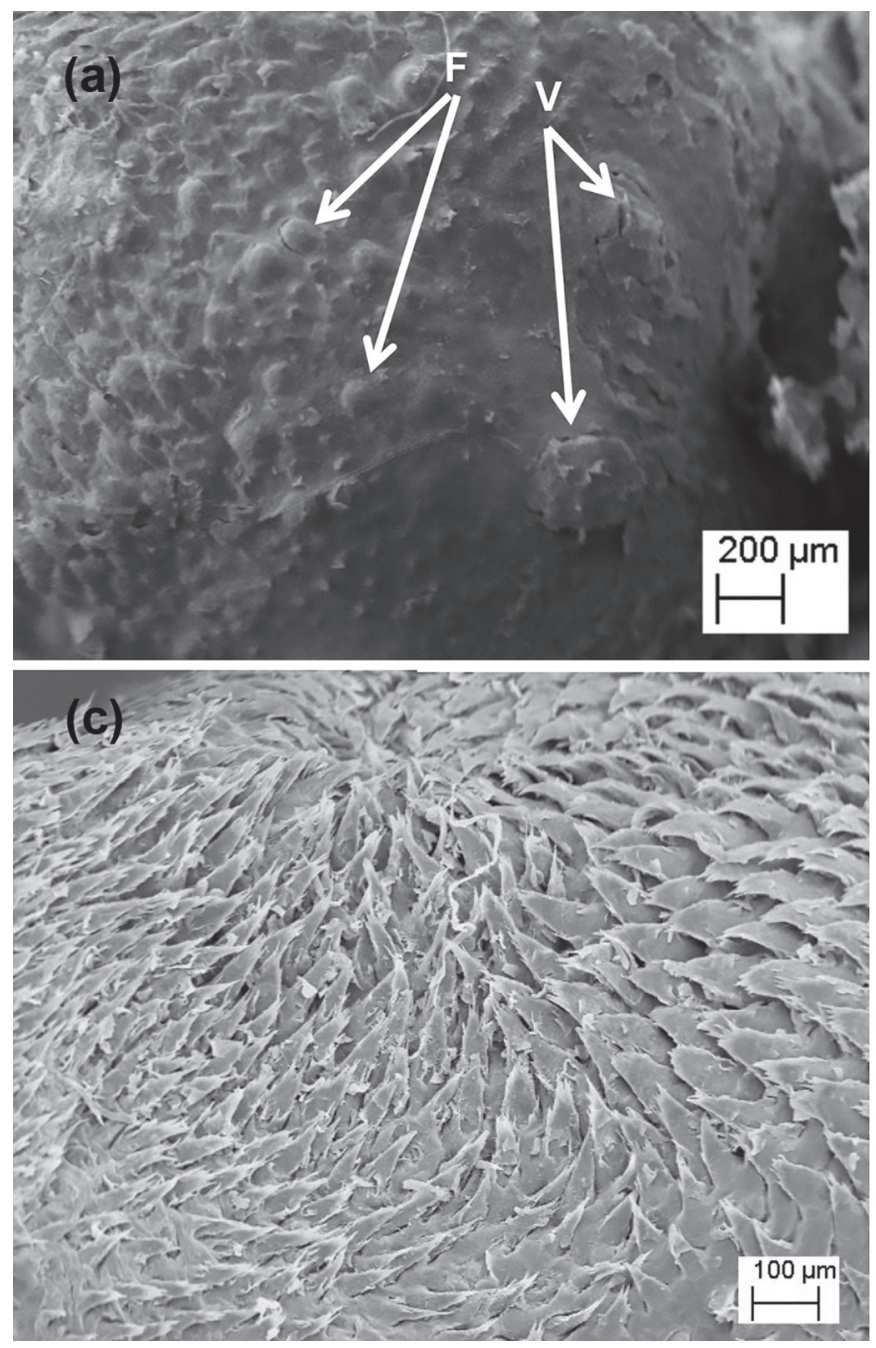

Superfamily Noctilionoidea comprised of families Moormopidae, Thyropteridae, and Furipteridae Pteronotus rubiginosus (Mormoopidae) presented the greatest variation in the length/width ratio, ranging from 3.1 to 5.1 (Table 3), denoting that the tongue is longer than it is wide. The species presents the highest number of types of papillae among all taxa included in this study, and the tongue morphology resembles, in this aspect, that of the Phyllostomidae as described by Gimenez et al. (1996) and Wetterer et al. (2000). The tongue is robust, with a bare posterior region without any mechanical papillae; two pairs, one medial and one lateral, of typical circumvallate papillae, are present with a prominent membrane surrounding the groove. The lateral circumvallate papillae is slightly anterior to that of the dorsal. Anterior to the dorsal circumvallate papillae, the dorsal and lateral portions of the tongue are covered by transverse lines of crown filiform papillae (Fig. 4A), mingled with scattered fungiform papillae. The latter is distinct from other fungiform papillae in having a sulcus, being very wide and oval-shaped (Fig. 4A), while the anteriormost fungiform papillae are typically globular. From the apex to the middle, the tongue is dorsally and laterally covered by digitiform filiform papillae (Fig. 2G) that are
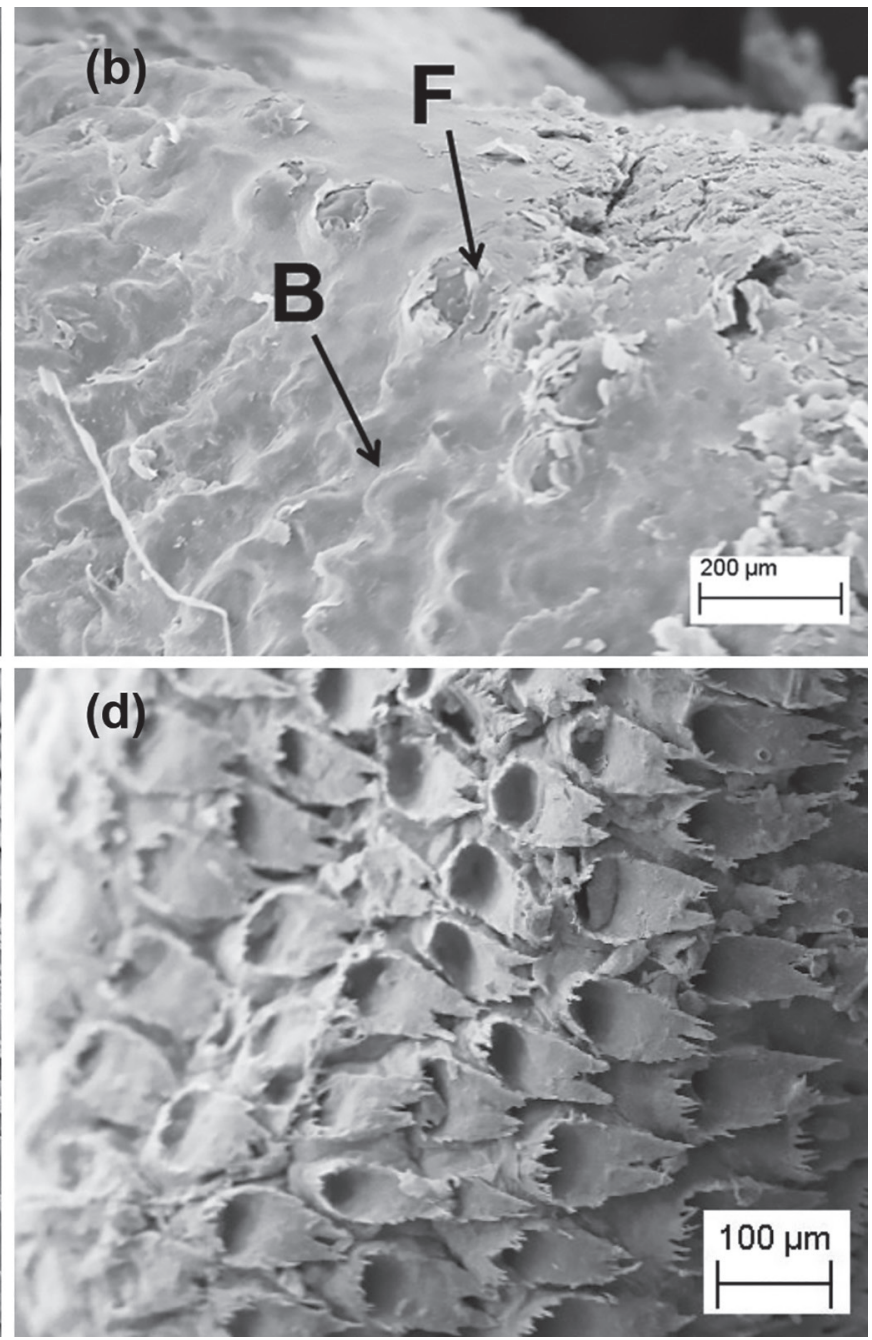

Figure 3. Tongues of Emballonuridae (Emballonuroidea): (a) Circumvallate papillae (V) with the groove and surrounding incipient tegument and fungiform papillae (F) to the left of the circumvallate papillae in Peropteryx kappleri; (b) Lateral fungiform papillae (F) and low basal filiform papillae (B) in P. kappleri; (c) Strictly filiform papillae concentrically arranged at the middle region of the tongue in Rhynchonycteris naso; and (d) Bifid filiform tubular-shaped papillae at the apex in P. kappleri. 
posteriorly directed. There is a dorsal island of giant papillae near the apex, and they are bulbous and slightly bifid at the posterior edge (Fig. 2F).

Thyroptera wynneae (Thyropteridae) presents the narrowest tongue among the studied taxa with a long posterior portion (Table 3); as a result, the species presents the highest length/width ratio, 4.1. No posteromedial lobe or salience at the mid-dorsal portion of the tongue was observed. The tongue resembles that from Pteronotus in having two pairs of circumvallate papillae (dorsal and lateral), and the anterior region of the tongue, from the apex to the middle, is covered by digitiform filiform papillae posteriorly directed (Fig. 2G). However, circumvallate papillae stand out with a large and salient membrane surrounding the groove, and the posterior portion of the tongue is covered by pointed and monofid basal filiform papillae (Fig. 2l). The middle region is dorsally covered by small, monofid, and pointed strictly filiform papillae mingled with many globular and large fungiform papillae (Fig. 4B).

The general shape of the tongue in Furipterus horrens (Furipteridae) resembles Thyroptera in having a long
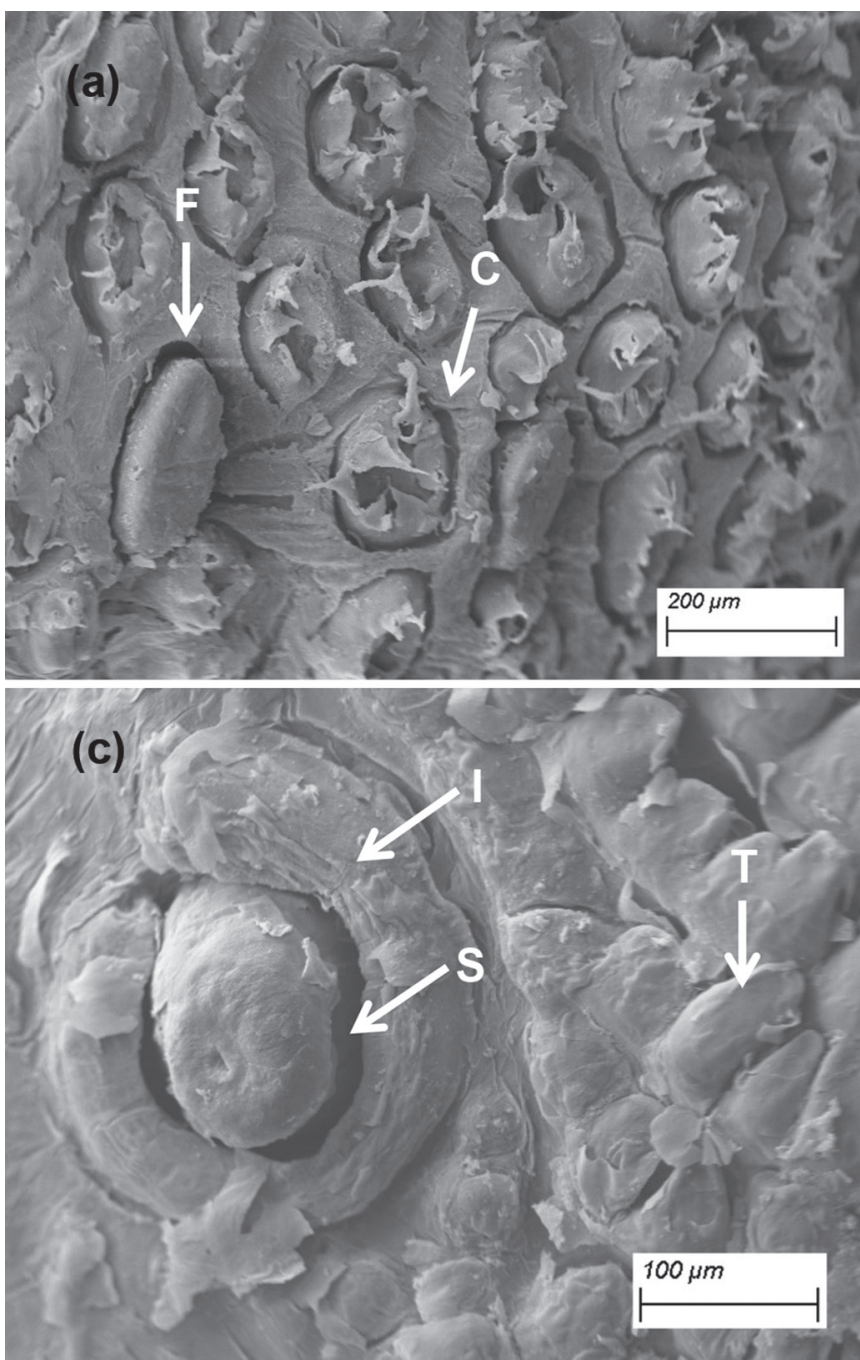

posterior region (Table 3), but with the smallest length/ width ratio varying between 2.3 and 2.8. No dorsal lobe or salience at the middle portion of the tongue was observed. The lateral and posterior regions of the tongue, dorsally, are naked, consisting of only a pair of prominent circumvallate papillae. Anterior to these circumvallate papillae, a series of dorsal and lateral triangular filiform papillae are present (Fig. 4C). The anterior region of the tongue, from the apex to the middle, is covered by strictly filiform papillae; they are long, filamentous (Fig. 4D), and posteriorly directed from the apex, and become shorter, monofid, and concentrically directed at the middle region. There are no basal filiform papillae. Fungiform papillae, when present, are scarce.

Superfamily Vespertilionoidea, families Natalidae, and Vespertilionidae - Natalus macrourus (Natalidae) present a long and narrow tongue, with a relatively long posterior region (Table 3 ); the length/wide ratio is 3.0 to 3.3. There are three circumvallate papillae at the dorsal surface (Fig. 5C); they are weakly grooved and the membrane surrounding the sulcus is incipient. An anterior and centered circumvallate papilla is present anterior to the
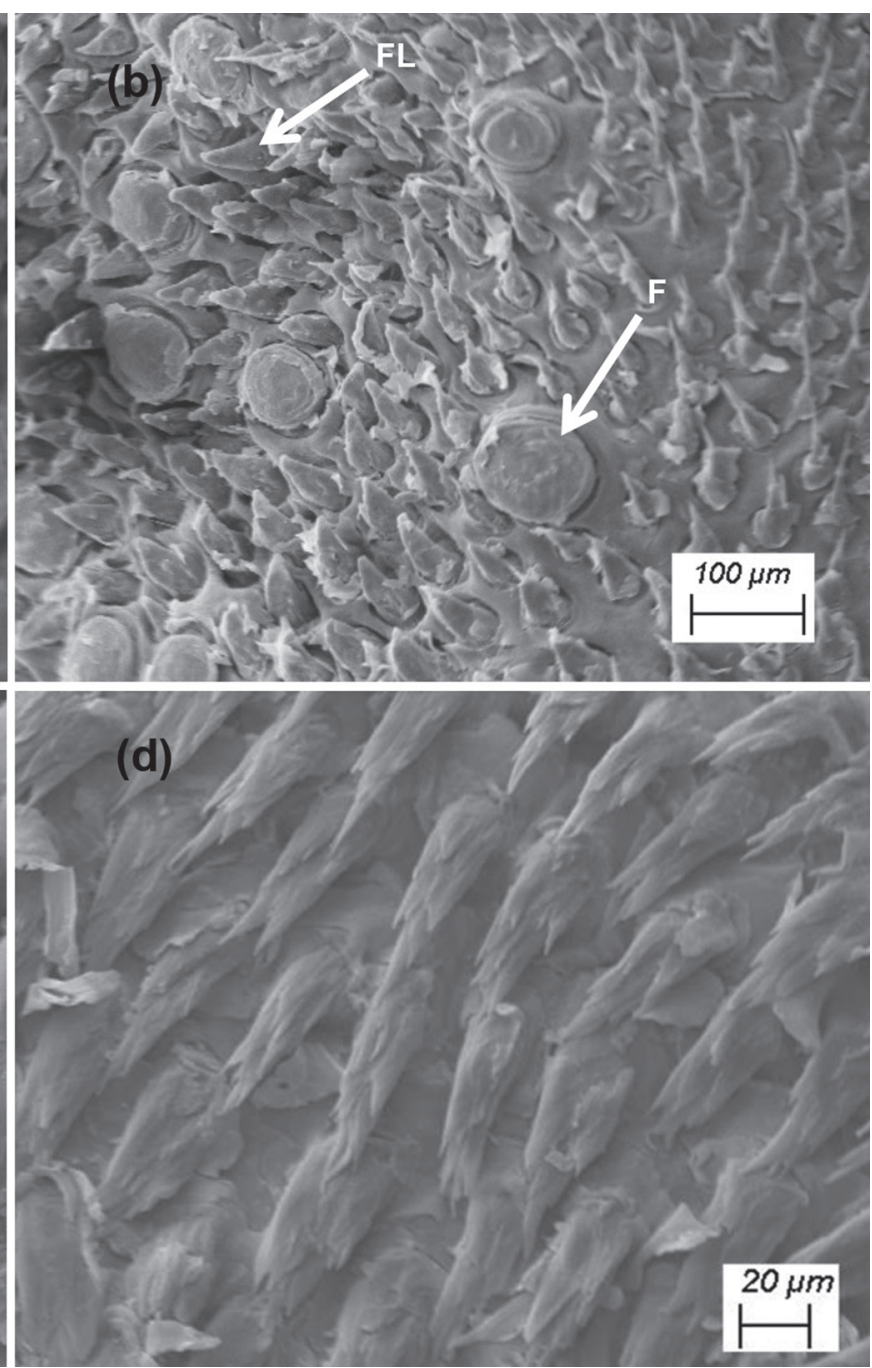

Figure 4. Tongues of Noctilionoidea, families Mormoopidae, Thyropteridae, and Furipteridae; (a) Oval and grooved fungiform (F) surrounded by crown filiform papillae (C) in Pteronotus rubiginosus; (b) Globular fungiform (F) surrounded by short and pointed strictly filiform papillae (FL) in Thyroptera wynneae; (c) Posterior region with large medial circumvallate with prominent sulcus $(S)$ and surrounding integument (I), and triangular filiform papillae (T) in Furipterus horrens; and (d) Striclty filiform papillae at the apex in F. horrens. 
pair posteriorly placed (Fig. 5C). Whole dorsal and lateral portions surrounding the dorsal circumvallate papillae are densely covered by large and monofid basal filiform
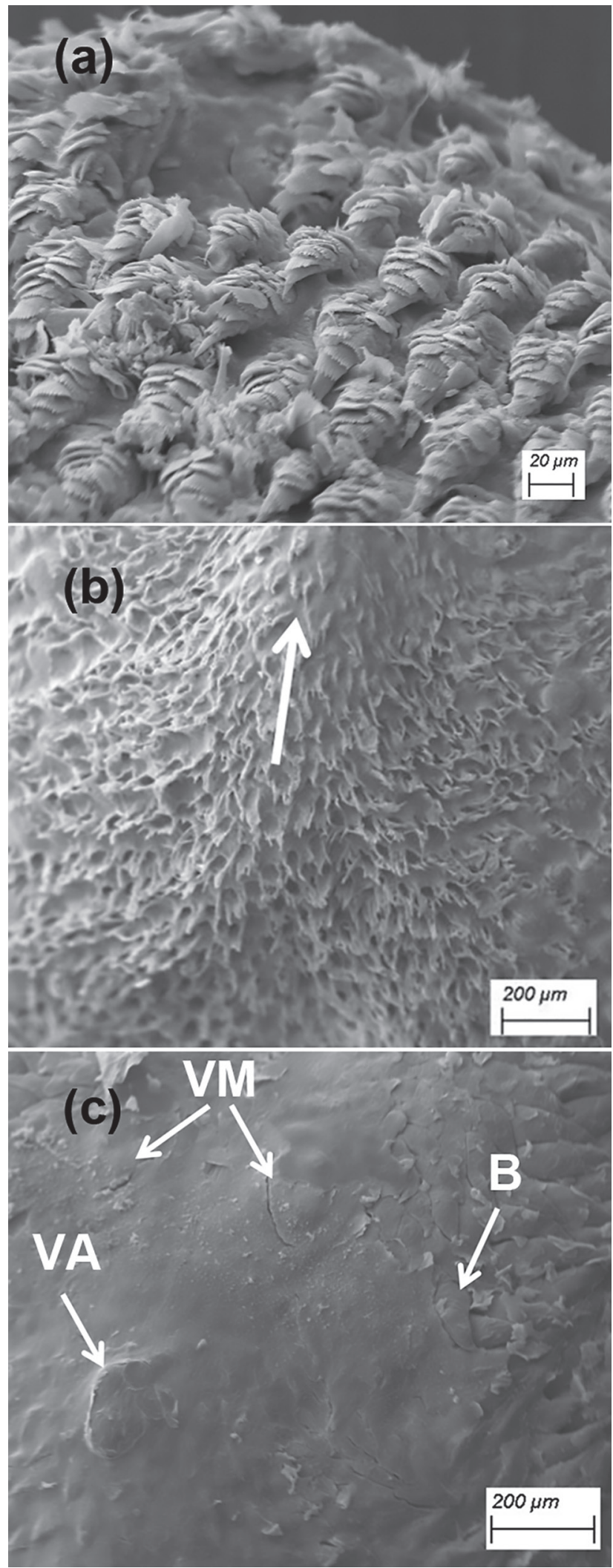

Figure 5. The tongue of Vespertilionoidea, family Natalidae, Natalus macrourus: (a) Apex covered by flaky-shaped filiform papillae; (b) Salience (arrow) on mid-dorsal region of the tongue; and (c) Posterior region of the tongue with three circumvallate papillae, one anterior (VA) and two posteriorly placed (VM) and pointed basal filiform papillae (B). papillae (Fig. 5C). From and anterior to the circumvallate papillae, a longitudinal salience lifts and is covered by transversal rows of small strictly filiform papillae (Fig. 5B). The anterior portion of the tongue is covered by a peculiar type of filiform papillae never seen in literature nor the taxa studied by the authors of this paper. These papillae are wider at the base and sharper at the tip, and they are composed of several large and dentate keratinous, ventrally curved plates (Figs. 2E, 5A); Those papillae are larger at the apex than along the lateral and into the middle of the tongue. Globular fungiform papillae were observed beside the mid-dorsal prominence and linearly arranged along the laterodorsal portion of the tongue (Fig. 5B).

Histiotus velatus, Lasiurus blossevillii, and Eptesicus spp. (Vespertilionidae) presented some similarities in tongue morphology, with a median length/width ratio, varying between 2.2 and 3.4 (Table 3). All species also presented a basal portion of the tongue with a central region from the glottis to dorsal circumvallate papillae naked, with no filiform papillae (Fig. 6A). A salience (Eptesicus and Histiotus) (Fig. 6B) or a lobe (Lasiurus) at the mid-portion of the tongue was observed. There was only a pair of dorsal circumvallate papillae, with a well-developed groove, surrounding tegument, and a lobed central portion (Fig. 6A). Fungiform papillae are large and usually scattered over the whole tongue. Bifid filiform papillae cover the apex and are posteriorly directed; bifid filiform papillae become simpler along the lateral and mid-posterior region of the tongue, where strictly filiform papillae are located. On the dorsal salience, at the middle portion of the tongue, concave or tubular scale-like filiform papillae (Fig. 6D) are outwardly directed from the center. Basal filiform papillae are large, conical, slightly curved, numerous, and overlap each other (Fig. 6A). In H. velatus and L. blossevillii, globular fungiform papillae are distributed at the dorsal portion, from the circumvallate papillae to the anterior, where it has medial prominence, and the lateral of the tongue. In Eptesicus spp. fungiform papillae are distributed on and ahead of the medial salience only; they are larger than Histiotus and Lasiurus, and grooved.

\section{DISCUSSION}

In this study, the papillae were named based on three studies, and all papillae observed were described and illustrated (Fig. 2) to avoid any nomenclature confusion. The available names were applied as often as possible to keep relative stability of the names. In bats, there is an elevated number of names used for the mechanical papillae. An analysis of 11 studies dealing with bat tongue morphology, mostly of only one or a few species (e.g., Greenbaum \& Phillips, 1974; Kobayashi \& Shimamura, 1982; Pastor et al., 1993; Gimenez et al., 1996; Wetterer et al., 2000; Emura et al., 2001; Gregorin, 2003; Abumandour, 2014) revealed a range of three to nine types of filiform papillae described in each study. However, the total number of names used in all 11 stud- 
ies was 37, which suggests that at least some papillae have multiple names, or that there are extended names (subdivisions) referring to details of each filiform papilla (position, morphology). Thus, strictly filiform papillae (referred to as "thread") followed the study by Pastor et al. (1993), but these papillae were named "hair-like" by Kobayashi \& Shimamura (1982), "scale-like" by Emura et al. (2001) and Gregorin (2003), and "leaf-like" by Abumandour (2014). Giant filiform papillae were named "horny" by Gimenez et al. (1996), "bifid horny" by Park \& Hall (1951) and Greenbaum \& Phillips (1974), "giant filiform" by Abumandour (2014), and "trifid giant filiform" by Emura et al. (2001). Crown filiform papillae, here observed, are the same as described by Pastor et al. (1993) and Emura et al. (2001), but named "basketlike" by Park \& Hall (1951) and Wetterer et al. (2000). Basal filiform papillae were described by Kobayashi \& Shimamura (1982), Pastor et al. (1993), Emura et al. (2001), and Abumandour
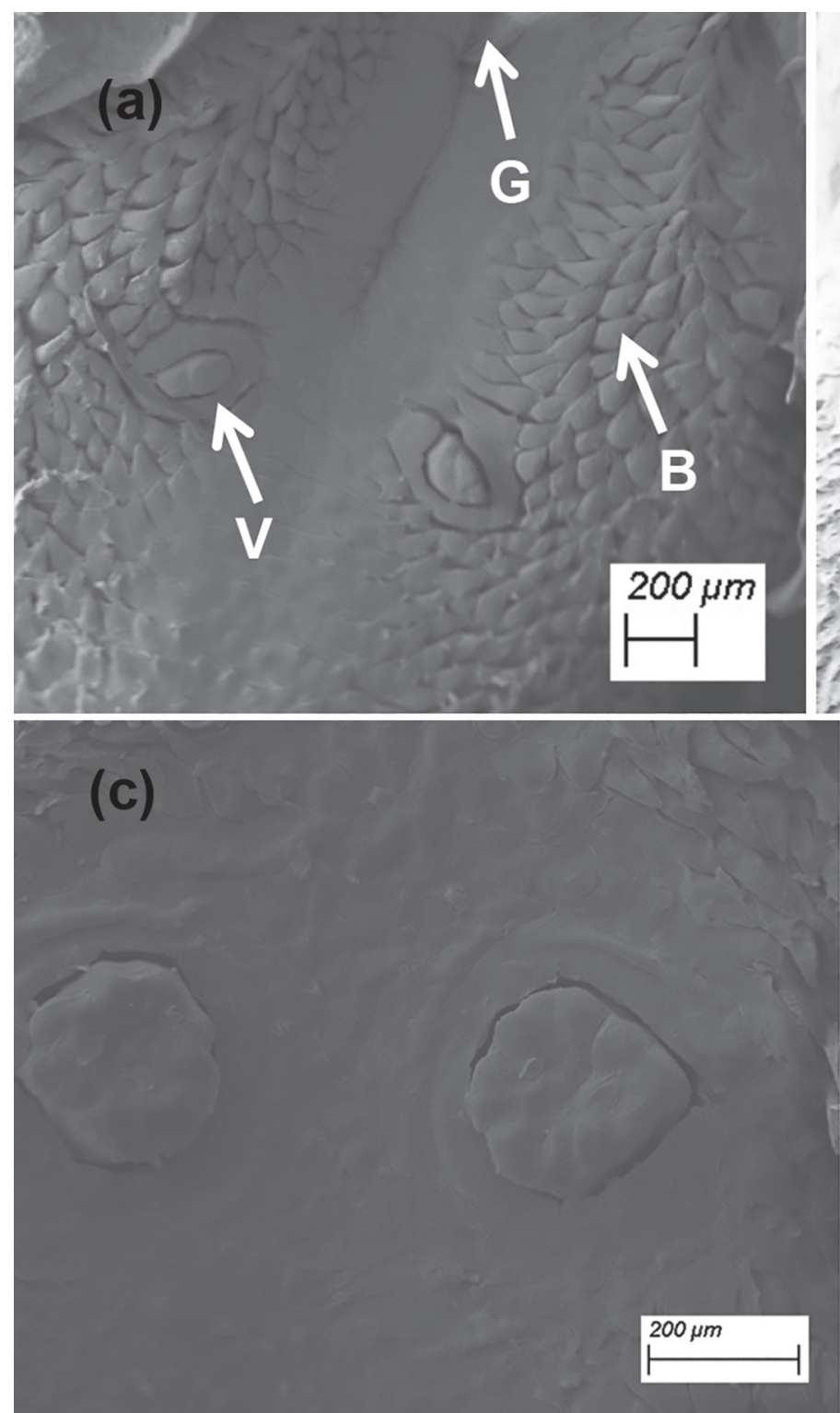

(2014) as "conical filiform papillae"; Greenbaum \& Phillips (1974) called the curved conical papillae "hooklike". Finally, "scale-like filiform papillae" were named by Gimenez et al. (1996) and described as "posteromedial" by Gregorin (2003).

Neotropical bats presented various shapes of the tongue among taxa, with Thyroptera and Pteronotus presenting the more elongated tongue (length/width ratio $\sim 4$ ) and Furipterus, the shortest (ratio 2.5) (Table 3), reflecting part of its skull (rostrum) morphology. Usually, a longer rostrum, in addition to other traits (e.g., dental structure, zygomatic robustness, and muscles), reflects in a weaker bite, and it is expected that bats with these traits consume small and soft insects (Santana, 2016). Indeed, Santana (2016) studied 20 phyllostomid species and found out that larger gapes result in a decrease in bite force. Another intriguing observation is the presence of a prominent dorsal lobe at the mid-region of the
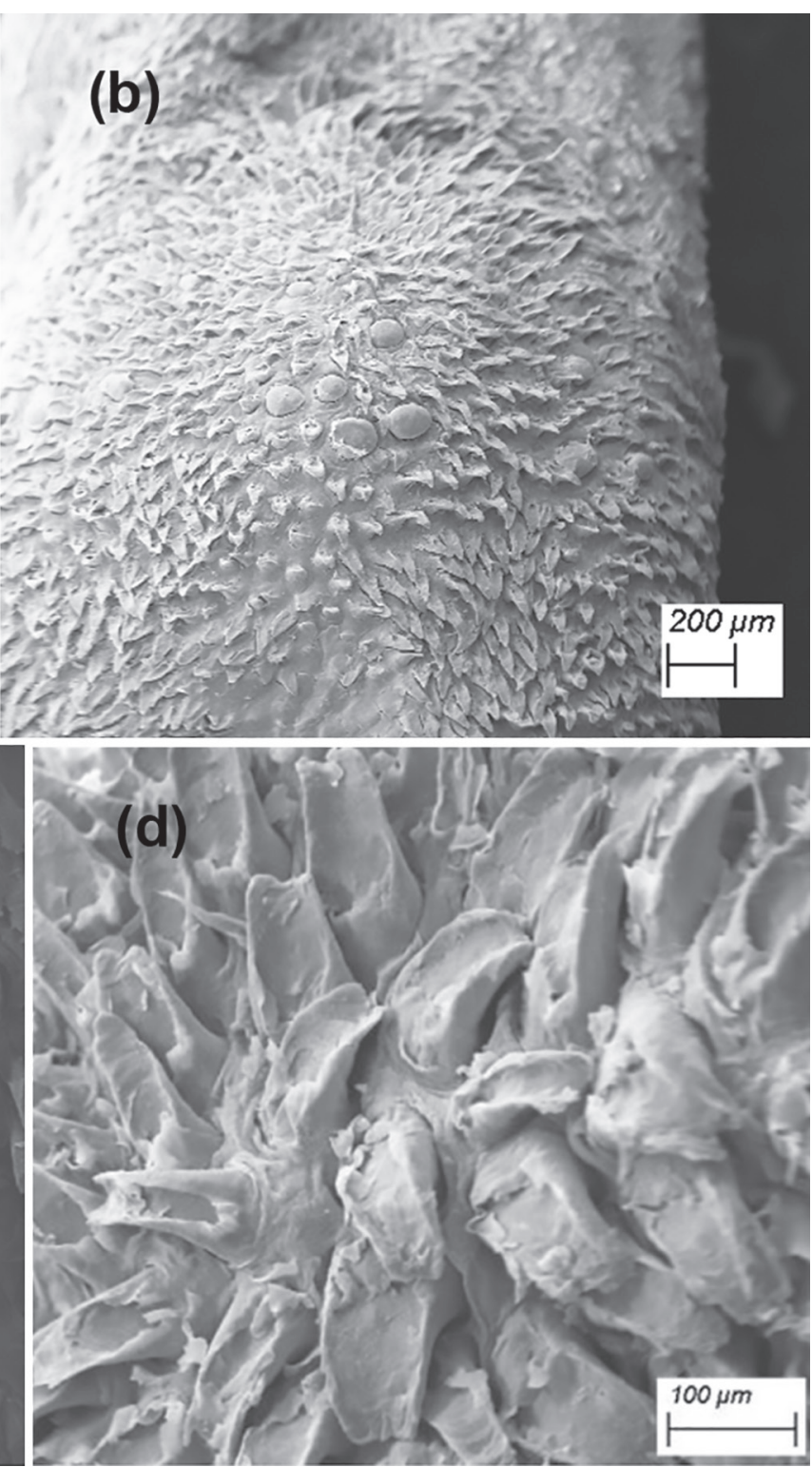

Figure 6. The tongue of Vespertilionoidea, family Vespertilionidae: (a) Posterior region of the tongue with a pair of circumvallate papillae (V) and the conical basal papillae (B) in Histiotus velatus. Note the naked central portion between circumvallate papillae and the glottis (G); (b) Middle portion of the tongue with remarkable salience covered by scale-like filiform papillae with large fungiform papillae in Eptesicus furinalis; (c) Circumvallate papilla, note the lobed surface of the papilla in Eptesicus brasiliensis; (d) Scale-like filiform papillae on the mid-dorsal salience in $H$. velatus. 
tongue in Lasiurus and all free-tailed bats (Molossidae) as observed by Gregorin (2003). Lasiurus and most molossid bats have a proportionally short rostrum (compared to the braincase, for example), but the function of their lingual lobe is unknown since the diet of a speciose group such as molossid is quite varied. However, some free-tailed bats (like Eumops, Nyctinomops, and Otomops) present a relatively long rostrum. Indeed, the distribution of characters on a constrained tree (Fig. 7) revealed many convergences among species from distinct families. The tongues of all bats studied here and those previously described in literature always presented a pair of circumvallate papillae at the posterodorsal portion of the tongue, but Natalus macrourus presented a third circumvallate papilla placed anterior to the dorsal pair (Fig. 5). Three dorsal circumvallate papillae are rare in bats, and they have only been recorded in the flying-fox $R$. aegyptiacus (Jackowiak et al., 2009). Only Noctilionoidea bats, except for Noctilio, presented a pair of circumvallate papillae on the side of the tongue, which was probably lost (derived condition) in the bulldog bats (Wetterer et al., 2000). Emballonuridae, Vespertilionidae, Molossidae, and Noctilionidae present lateral fungiform papillae, but only the latter two have them linearly arranged (Gregorin, 2003). Giant papillae are present in Noctilionidae,
Mormoopidae, and Phyllostomidae (Gimenez et al., 1996; Wetterer et al., 2000). Most Neotropical aerial insectivore bats do not present this kind of papillae. Finally, part of the filiform papillae is present only in one or two taxa; such as triangular filiform in Furipterus, flaky-shaped filiform in Natalus, developed scale-like filiform papillae in Molossidae (Gregorin, 2003), and digitiform filiform papillae in Thyroptera and Pteronotus.

Phylogenetically, aerial insectivore bats here studied are grouped in three distinct lineages as recovered by robust molecular phylogeny (Teeling et al., 2005): Emballonuroidea, represented by Emballonuridae; Noctilionoidea, represented by Thyropteridae + Furipteridae + Mormoopidae; and Vespertilionoidea, composed of Natalidae + Molossidae + Vespertilionidae. All three superfamilies represent the three main branches composing the suborder Yangochiroptera, with Emballonuroidea, sister-group of Vespertilionoidea + Noctilionoidea (Fig. 7). It was observed that Emballonuridae presented the simplest tongue structure, with a low and delicate basal and strict filiform papillae, and the general structure can be plesiomorphic to Yangochiroptera. Noctilionoidea + Vespertilionoidea presented more complex tongue surfaces, with more types, developed taste, and filiform papillae. All Noctilionoidea

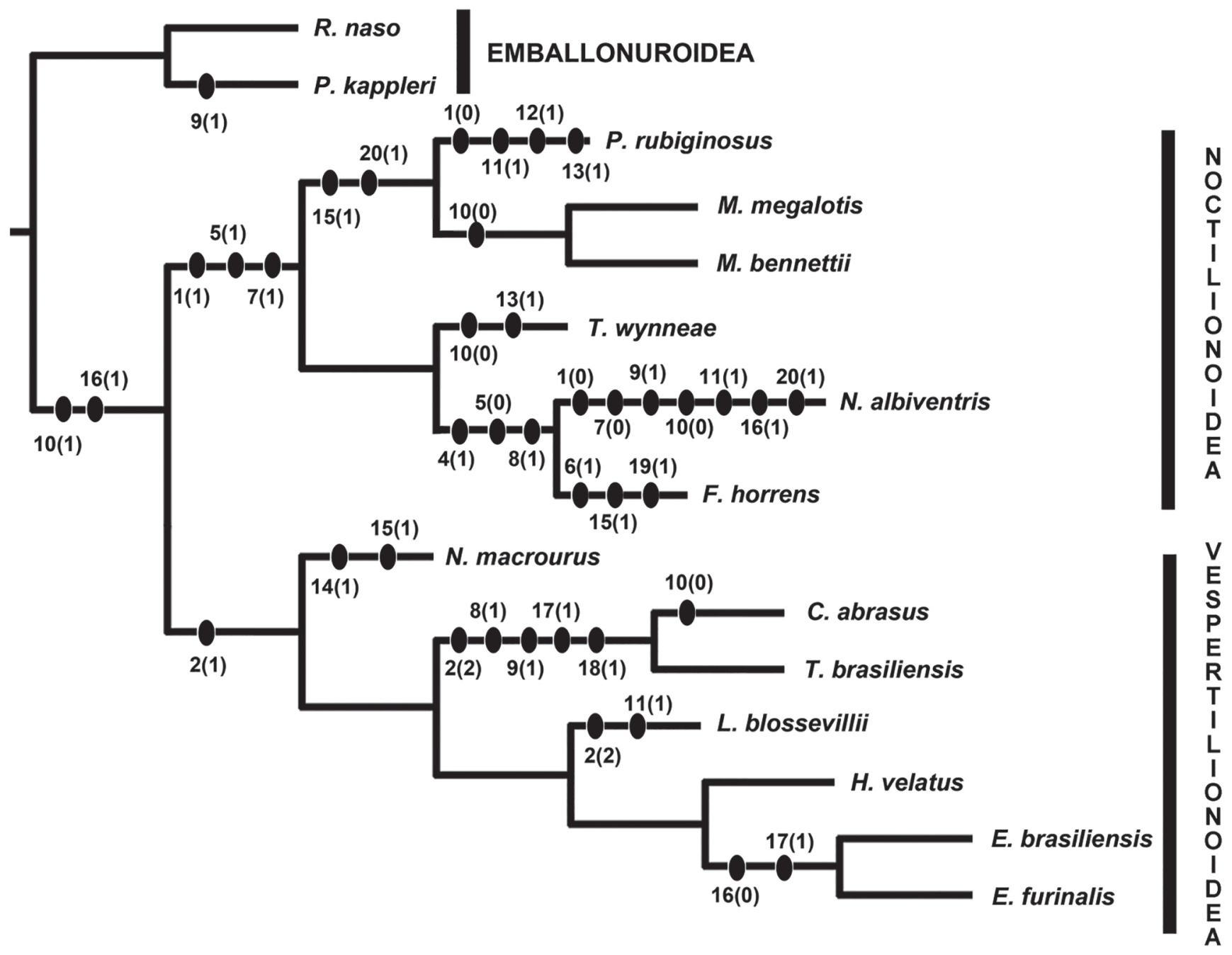

Figure 7. Constrained bat phylogeny and the fittest distribution of characters and their respective state (in parentheses). The coding of characters among the taxa is in Table 2. 
families presented small and non-grooved fungiform papillae, but the bifid filiform papillae were lacking. A long posterior region of the tongue (Ch 1$)$, the presence of circumvallate lateral papillae (Ch 5), and the absence of lateral fungiform papillae ( $\mathrm{Ch}$ 7) are putative synapomorphies of this superfamily (with some character's reversions) (Fig. 7). Some convergences were observed, like Thyropteridae and Mormoopidae, presenting fungiform papillae distributed along the lateral and anterior dorsum of the tongue, and both taxa presented digitiform filiform papillae not observed in Phyllostomidae, Noctilionidae, and Furipteridae. All three families within Vespertilionoidea presented the same level of dorsal elevation at the middle of the tongue, being a salient (Natalidae and most of Vespertilionidae) (Ch 2, state 1 Fig. 7) or a very prominent lobe as observed in Lasiurus (Vespertilionidae) and all Molossidae (Gregorin, 2003) (Ch 2, state 2 - Fig. 7).

However, even some similar papillae can be phylogenetically shared (putative synapomorphies). Part of the observed papillae occur in phylogenetic distant taxa, so although phylogeny certainly could explain some papillae traits among studied taxa, much of the observed papillae may be functional homologies (e.g., convergence) and could be explained by diet and feeding ecology. Several eco-morphological studies have focused on three fundamental and interrelated attributes of bats: echolocation, flight, and dietary diversity, and have tentatively summarized the species into the trophic guilds. Dietary diversity has a direct relation with the modification of the cranio-dental structure, mandible, and musculature morphology (Freeman 1979; Aguirre et al., 2003; Monteiro \& Nogueira, 2011; Santana, 2016; Rossoni et al., 2019). For example, free-tailed bat (Molossidae) species were classified as beetle- and moth-eating bats (Freeman, 1979), and both groups were characterized by a set of morphological traits as a result of several selective pressures. It is then expected that the first group presents more robustness of the molars and mandible, a higher coronoid process of the mandible, massive masticatory muscles (e.g., pterygoid, masseter, and temporalis), and a dome-shaped skull with the presence and development of skull crests (e.g., sagittal, paroccipital, and nuchal), but nothing is said about tongue morphology. This general morphological pattern in musculature and cranio-dental complexes is related to structural and mechanical attributes of the prey (e.g., hardness, texture, and size) (Freeman, 1979). On the other hand, most papers focusing on insect-eating bats provide only a familial level of insects and this general classification does not precisely permit to relate the species preyed upon to the morphological traits of bats. Besides that, no study has focused on the functional and physiological aspects. Thus, although many gaps were detected in the comprehension of feeding eco-morphology and the low sampling of taxa was clear, this study provides a first step in understanding the relationships among the tongue morphology of some Neotropical aerial insectivore bats and their feeding ecology. It describes the general structure of the tongue surface and the papillae, particularly the diversity of filiforms. The continued research and observation of how bats manipulate food and what item is consumed is encouraged, but the authors notice that it is a hard challenge to study those mechanisms as most Neotropical insectivore bats are hardly sampled in nature and even basic biological data is lacking. On the other hand, this study enables the inclusion of the tongue morphological complex in broad future phylogenies including morphology.

\section{ACKNOWLEDGMENTS}

The authors would like to thank the team of Electron Microscopy Laboratory at UFLA (LME), under the coordination of Dr. Eduardo Alves, for all assistance and permission in using the equipment and facilities. We are indebted to Jaleesa Clarke for proofreading the English. This study was partially funded by CNPq processes 303382/2016-3 and 402330/2016-1.

\section{AUTHORS' CONTRIBUTIONS}

R.G.: Conceptualization, Methodology, Writing original draft, Investigation. Writing - review \& editing. P.A.Z.: Material preparation, Analysis, Writing.

\section{CONFLICTS OF INTEREST}

There is no conflict of interest.

\section{REFERENCES}

Abayomi, T.A.; Ofusori, D.A.; Ayoka, 0.A.; Odukoya, S.A.; Omotoso, E.0.; Amegor, F.0.; Ajayi, S.A.; 0jo, G.B. \& Oluwayinka, 0.P. 2009. A comparative histological study of the tongue of rat (Rattus norvegicus), bat (Eidolon helvum) and Pangolin (Manis tricuspis). International Journal of Morphology, 27(4): 1111-1119.

Abumandour, M. 2014. Morphological comparison of the filiform papillae of New Zealand white rabbits (Oryctolagus cuniculus) as domestic mammals and Egyptian fruit bat (Rousettus aegyptiacus) as wild mammals using scanning electron microscopic specimens. International Journal of Morphology, 32(4): 1407-1417.

Aguirre, L.; Herrel, A. \& Van Damme, M.E. 2003. The implication of food hardness for diet in bats. Functional Ecology, 17(2): 201-212. DOI

Emura, S.; Hayakawa, D.; Chen, H.; Shoumura, S.; Atoji, Y. \& Agungpriyono, S. 2001. SEM study on the dorsal lingual surface of the lesser dog-faced fruit bat, Cynopterus brachyotis. Okajimas Folia Anatomica Japonica, 78: 123-128. DOI

Ferrarezzi, H. \& Gimenez, E.A. 1996. Systematic patterns and the evolution of feeding habitats in Chiroptera (Mammalia: Archonta). Journal of Comparative Biology, 1:75-94.

Freeman, P.W. 1979. Specialized insectivory: Beetle-eaten and moth-eaten molossid bats. Journal of Mammalogy, 60(3): 467-479.

Freeman, P.W. 1998. Form, function, and evolution in skulls and teeth of bats. In: Kunz, T.H. \& Racey, P.A. (Eds.). Bat biology and conservation. Washington DC, Smithsonian Institution Press. p. 140-156. 
Freeman, P.W. 2000. Macroevolution in Microchiroptera: recoupling morphology and ecology with phylogeny. Evolutionary Ecology Research, 2:317-335.

Gardner, A.L. 1977. Feeding habits. In: Barker, R.J.; Jones-Jr., J.K. \& Carter, D.C. (Eds.). Biology of bats of the New World family Phyllostomatidae, Part 2, Endoparasites. Special Publication Museum of Texas Tech University, 13: 1-364, 293-350.

Gimenez, E.A. 1993. Morfologia lingual comparada, filogenia e evolução dos hábitos alimentares na superfamília Phyllostomoidea (Mammalia: (hiroptera). Universidade Estadual Paulista, Botucatu (Master Thesis).

Gimenez, E.A.; Ferrarezzi, H. \& Taddei, V.A. 1996. Lingual morphology and cladistics analysis of the New World nectar-feeding bats (Chiroptera: Phyllostomidae). Journal of Comparative Biology, 1: 41-63.

Goloboff, P.A.; Farris, J.S. \& Nixon, K.C. 2008. TNT, a free program for phylogenetic analysis. Cladistics, 24: 774-786.

Greenbaum, I.F. \& Phillips, C.J. 1974. Comparative anatomy and general histology of the tongues of long-nosed bats (Leptonycteris sanborni and $L$. nivalis), with reference to infestation of oral mites. Journal of Mammalogy, 55: 489-504.

Gregorin, R. 2003 Comparative morphology of the tongue in free-tailed bats (Chiroptera, Molossidae). Iheringia, Zoologia, 93: 213-221. DOI

Griffths, T.A. 1982. Systematics of the New World nectar-feeding bats (Mammalia, Phyllostomidae), based on the morphology of the hyoid and lingual regions. American Museum Novitates, 2742: 1-45.

Griffths, T.A. \& Criley B.B. 1989. Comparative lingual anatomy of the bats Desmodus rotundus and Lonchophylla robusta (Chiroptera: Phyllostomidae). Journal of Mammalogy, 70: 608-613.

Harper, C.J.; Swartz, S.M. \& Brainerd, E.L. 2013. Specialized bat tongue is a hemodynamic nectar mop. Proceedings of the National Academy of Sciences, 110: 8852-8857. DOI

Howell, D.J. \& Hodgkin, N. 1976. Feeding adaptation in the hairs and tongues of nectar-feeding bats. Journal of Morphology, 148: 329-336.

Jackowiak, H.; Trzcielinska-Lorych, J. \& Godynicki, S. 2009. The microstructure of lingual papillae in the Egyptian fruit bat (Rousettus aegyptiacus) as observed by light microscopy and scanning electron microscopy. Archives of Histology and Cytology, 72: 13-21. D01
Kobayashi, S.\& Shimamura, A. 1982. Comparative anatomical observations of the tongue of the Japonese long-fringered bats, Miniopterus schreibersi fuliginosus. Okajimas Folia Anatomica Japonica, 58: 923-932. D0l

Monteiro, L.R. \& Nogueira, M.R. 2009. Adaptative radiations, ecological specialization, and the evolutionary integration of complex morphological structures. Evolution, 64: 724-744. D0I

Monteiro, L.R. \& Nogueira, M.R. 2011. Evolutionary patterns and processes in the radiation of phyllostomid bats. BMC Evolutionary Biology, 11. D0I

Park, H. \& Hall, E.R. 1951. The gross anatomy of tongues and stomachs of eight New World bats. Transactions of the Kansas Academy of Science, 54: 64-72.

Pastor, J.F.; Moro, J.A.; Verona, J.A.G.; Gato, A.; Represa, J.J. \& Barbosa, E. 1993. Morphological study by scanning electron microscopy of the lingual papillae in the common European bat (Pipistrellus pipistrellus). Archives of Oral Biology, 38: 597-599. DOI

Rossoni, D.M.; Costa, B.M.A.; Giannini, N.P.\& Marroig, G. 2019. A multiple peak adaptative landscape based on feeding strategies and roosting ecology shaped the evolution of cranial covariance structure and morphological differentiation in phyllostomid bats. Evolution, 73: 961-981. D01

Santana, S.E. 2016. Quantifying the effect of gape and morphology on bite force: biomechanical modeling and in vivo measurements in bats. Functional Ecology, 30: 557-565. DOI

Simmons, N.B. \& Conway, T.M. 2003. Evolution of Ecological Diversity in Bats. In: Kunz, T.H. \& Fenton, M.B. (Eds.). Bat Ecology. The University of Chicago Press, Chicago, 493-57.

Teeling, E.C.; Springer, M.S.; Madsen, 0.; Bates, P.; 0'Brien, S.J. \& Murphy, W.J. 2005. A molecular phylogeny for bats illuminates biogeography and the fossil record. Science, 307: 580-584. DOI

Uieda, W. 1986. Aspectos da morfologia lingual das três espécies de morcegos hematófagos (Chiroptera, Phyllostomidae). Revista Brasileira de Biologia, 46: 581-587.

Wetterer, A.L.; Rockman, M.V. \& Simmons, N.B. 2000. Phylogeny of phyllostomid bats (Mammalia: Chiroptera): Data from diverse morphological systems, sex chromosomes, and restriction sites. Bulletin of the American Museum of Natural History, 248: 1-200. 